\title{
Application of QFD in China's Higher Education: A Bibliometric Study
}

\author{
Jinhong Zhong, Aoqi Guo, Yi Fu, Hongye Wang \\ School of Management, Hefei University of Technology, Hefei 230009, China
}

Keywords: Quality function deployment, Higher education, Bibliometric analysis, Social network analysis

\begin{abstract}
Quality function deployment (QFD) is a customer-driven product development approach, which has been applied by many authors to improve the quality of higher education. By employing SATI3.2, RStudio, Ucinet6.0, we make a bibliometric analysis for the papers on QFD application in China higher education, which are catalogued by CNKI from 1999 to 2017. By analyzing the information of year, periodical, organization, author and citation frequency for the papers in this field, this paper obtains the periodical distribution, main organization, active author and literature of high citation. Through clustering analysis, association rule analysis and social network analysis of high frequency keywords, this paper obtains the research hotspot and frontier of QFD application in China higher education.
\end{abstract}

\section{Introduction}

Higher education is an indispensable institution in the knowledge-based society [1], which is highly valued by the state and all sectors of society. At present, China higher education has made remarkable progress in the Educational Scale, the school running level, and the disciplinary development. There are also many studies on the improvement of higher education itself.

QFD is a technique to transform customer demand into quality requirements of product, service or production service system [2], which has been widely used to improve the quality of higher education. Chan and $\mathrm{Wu}$ [3] review the research progress of QFD from the aspects of history, functional fields, application industries, method development and citation frequently. However, their research is not specifically targeted at higher education. Moreover, the last literature is published in 2001 and there is a lack of review of Chinese literature. Sun and Chen [4] review the application of QFD in the quality improvement of higher education from the aspects of curriculum system design, the evaluation and improvement of education system quality and curriculum teaching quality, as well as other aspects. The last literature reviewed by them is released in 2007. However, the qualitative methods used in $[3,4]$ are based on authors' personal judgment. Therefore, it is necessary to analyze the latest development of QFD in China higher education and identify the future research from a quantitative and empirical perspective. To the best of our knowledge, there is no quantitative research in this field. In order to deepen the research in this field, we make a bibliometric analysis of the subject.

\section{Data sources and research methods}

In this paper, China National Knowledge Infrastructure (CNKI) database is used as the source of data acquisition. The advanced search strategy is: the title = ("QFD" or "Quality function deployment" or "House of quality" or "HOQ") and the title = ("education" or "talent" or "course") (exact match), and search time is 1999-2017. A total of 99 related literatures are obtained by screening and removing the literature irrelevant to the topic as well as duplicated literature.

Based on the external characteristics of the literature, a descriptive statistical analysis [5] is conducted to obtain the annual number, author distribution, journal distribution, institutional distribution and high-cited literature distribution of the literature in this field.

Based on the keywords in the literature, the co-word analysis is carried out. Through word frequency analysis, we construct the high frequency keyword word matrix and co-occurrence 
matrix, then we carry out association rule analysis, cluster analysis and social network analysis, finally we can obtain research hotspots and research directions in this field.

\section{The analysis of external features on literature}

\subsection{The overall situation of the literature}

From 1999 to 2017, there are 99 research papers applied by QFD in the fields of higher education, including 84 journal articles, three doctoral dissertations, eight master dissertations, and four conference dissertations. Figure 1 shows the distribution of annual published articles. It can be seen that the application of QFD in China higher education field begin in 1999, then the field is in its infancy from 1999 to 2004 and the number of literatures show a wave-like growth trend after 2005.

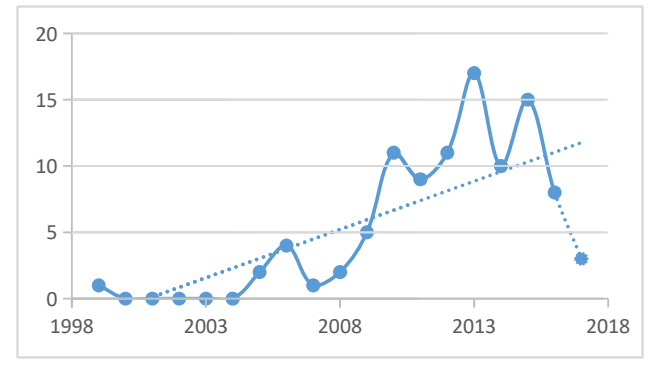

Figure 1 Annual number of published articles.

\subsection{The distribution of journals}

The research papers on the application of QFD in China higher education field are published in 69 academic journals, which are relatively scattered. According to the descending order of the quantity of articles carried, the distribution of the journals shown in Figure 2 is obtained. Among them, "Value Engineering" has the largest number of articles, including four articles; then followed by "Research and Exploration in Laboratory" and "China Management Informationization", both of which are three.

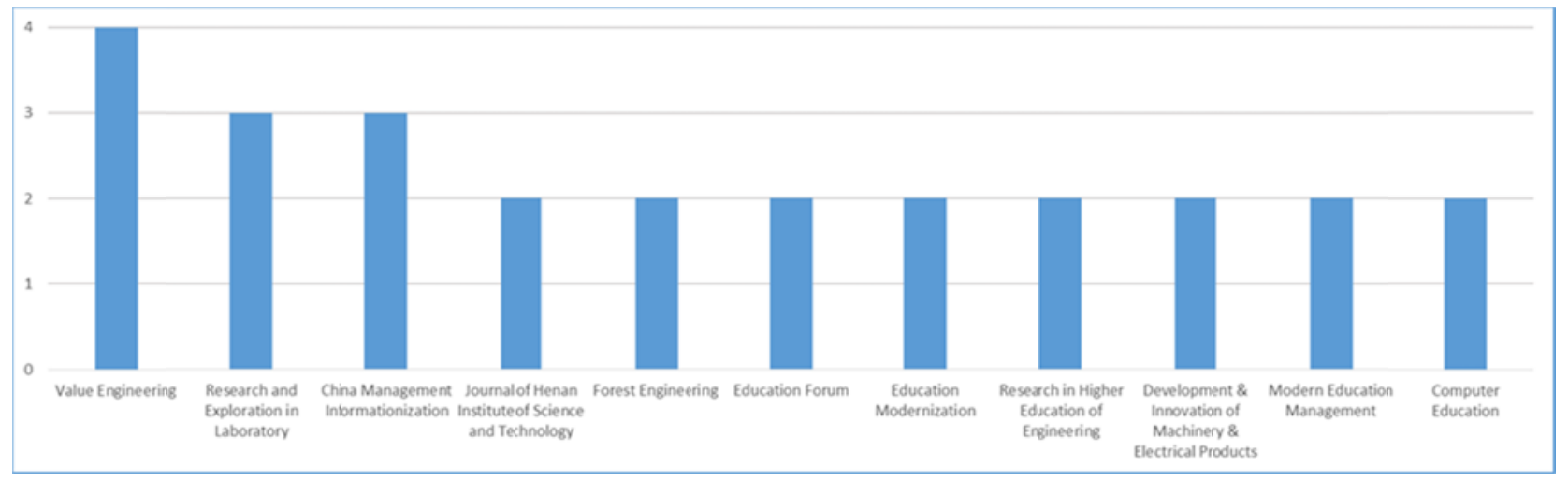

Figure 2 Distribution of the journals.

\subsection{The distribution of institutions}

The amount of institutional publications issued by institution reflects the level of scientific research strength and activity in a certain field. Based on the affiliation of the first author, the distribution of QFD's main institutions in higher education is shown in Table 1. Among them, Qingdao University publish the largest four papers; Panzhihua University and Hebei University of Technology both publish three papers; 15 universities including Zhejiang University publish two papers.

\subsection{The distribution of active authors}

In scientific research, the core author has high quality literature and strong academic influence in his research field. It is beneficial to analyze the research progress and contribution and guide the 
overall development of the field by learning the active authors in a certain field. The active author distribution of QFD applied in higher education is shown in Table 2. According to the Price formula, the core authors in this field are those who have published two or more papers.

Table 1 Main institutions and the number of papers published.

\begin{tabular}{cc|cc}
\hline Institution & No. & Institution & No. \\
\hline Qingdao University & 4 & Kunming University of Science And Technology & 2 \\
Panzhihua University & 3 & Huaiyin Institute of Technology & 2 \\
Hebei University of Technology & 3 & South China University of Technology & 2 \\
Zhejiang University & 2 & Hunan City University & 2 \\
Yanshan University & 2 & Heilongjiang Bayi Agricultural University & 2 \\
Northwestern Polytechnical University & 2 & Harbin University of Science And Technology & 2 \\
Xi`an FanYi University & 2 & Harbin Institute of Technology & 2 \\
Shanxi University of Science\& Technology & 2 & Dongbei University of Finance And Economics & 2 \\
Shenyang Normal University & 2 & Liaoning University & 2 \\
\hline
\end{tabular}

Table 2 Distribution of active authors.

\begin{tabular}{ccc|ccc}
\hline Author & Number & Percent (\%) & Author & Number & Percent (\%) \\
\hline Yilong An & 3 & 3.03 & Qiang Sheng & 2 & 2.02 \\
Fuhong Zeng & 2 & 2.02 & Hongqiao Song & 2 & 2.02 \\
Long Chen & 2 & 2.02 & Lili Song & 2 & 2.02 \\
Chao Zheng & 2 & 2.02 & Ming Wang & 2 & 2.02 \\
Chunfang Dong & 2 & 2.02 & Wei Wang & 2 & 2.02 \\
Guohong Feng & 2 & 2.02 & Lijun Yang & 2 & 2.02 \\
Mei Guo & 2 & 2.02 & Xu Zhao & 2 & 2.02 \\
Gongqian Liang & 2 & 2.02 & Zhiwen Zhu & 2 & 2.02 \\
\hline
\end{tabular}

The authors who publish a paper accounted for $91.21 \%$, which is far more than the proportion of $60 \%$ in Lotka's law. It indicates that most authors do not conduct further tracking, the person engaged in this research are scattered and a stable research group has not been formed yet.

\subsection{The distribution of highly cited papers}

The cited frequency reflects the status and social contribution of the paper in its field. Through the analysis of highly cited papers, we can learn the current research hotspots, core journals and overall level in this field. Table 3 shows the Top 8 highly cited papers of QFD in higher education. The paper "College Curriculum Teaching Design Based on QFD Theory" is cited the most frequently, 41 times. There are three articles cited at 20-30, and four articles cited at less than 20 times. Table 3 shows that the eight papers focus on teaching curriculum design, education quality management, experimental teaching and talent training. The publishing period is from 2005 to 2011 and the publishing institutions are Zhejiang University and Northwestern Polytechnical University, etc.

Table 3 Top 8 Highly cited papers.

\begin{tabular}{cc}
\hline Paper & Cited frequency \\
\hline College Curriculum Teaching Design Based on QFD Theory & 41 \\
Application of QFD in Quality Management of Domestic Higher Education & 28 \\
Quality Assurance Model of Graduate Education Based on QFD & 24 \\
College Teaching Quality Assurance System Based on QFD & 20 \\
Application of QFD in the Design of Teaching Curriculum Design & 15 \\
Quality Assurance System for Experiment Teaching of Industrial Engineering & 12 \\
in Universities Based on Quality Function Development & 12 \\
the Promotion of Educational Quality by QFD & 12 \\
Research on Quality Evaluation of Entrepreneurship Education Based on QFD & \\
\hline
\end{tabular}




\section{The subject analysis of literature}

\subsection{Keywords word frequency extraction and statistics}

Keyword is the central reflection of the paper' central idea, we can find out the subject of the paper through keyword analysis. We use SATI3.2 to obtain keywords and their frequencies, and make some dispose to keywords. For the keywords arranged in descending order of word frequency, we select the keyword whose frequency is greater than or equal to 2, then we get the high frequency keyword, as shown in Table 4.

Table 4 Keywords frequency (part).

\begin{tabular}{cc|cc}
\hline Keywords & Frequently & Keywords & Frequently \\
\hline Quality management & 14 & Evaluation system & 5 \\
Education quality & 13 & Economic management major & 5 \\
Curriculum provision & 10 & Talent training & 5 \\
Curriculum system & 9 & Training scheme & 5 \\
Teaching reform & 7 & Entrepreneurship education & 4 \\
User needs & 7 & Applied Talents & 4 \\
Teaching quality evaluation & 6 & Innovation ability & 4 \\
Industrial engineering & 6 & Practice teaching & 4 \\
Curriculum & 5 & Hotel management major & 3 \\
\hline
\end{tabular}

\subsection{Cluster analysis}

The purpose of cluster analysis is to obtain research subject in the field. We use SATI 3.2 to generate the co- word matrix of high frequency keywords. Then, we import the co-word matrix into RStudio, select Ward's method and Euclidean distance, and set the dendrogram into seven categories.

Category 1: Laboratory quality management. The keywords are laboratory, quality management system and PDCA cycle.

Category 2: Education quality evaluation. The keywords are education quality, teaching quality evaluation, quality control system, evaluation system and entrepreneurship education.

Category 3: The improvement of hotel management major curriculum system. The keywords are hotel management major, curriculum provision and curriculum improvement.

Category 4: Talent training scheme and quality management. The keywords are talent training, training scheme, curriculum needs, practical teaching, teaching reform, quality management and quality characteristic.

Category 5: The improvement of the training mode for industrial engineering and economic management majors. The keywords are industrial engineering, economic management majors, vocational ability, management talent, training model, curriculum system and teaching model.

Category 6: Innovative talent training. The keywords are innovative talents, innovation ability, TRIZ and talent training quality.

Category 7: Application of practical talents training. The keywords are applied talents, practical ability, training system, user needs, and production operation management.

\subsection{Association rules analysis}

The association rule analysis is based on the word matrix to analyze the relationship between high frequency keywords. First, SATI3.2 is used to generate the word matrix of high frequency keywords. Then, we import the word matrix into RStduio and select Apriori algorithm for association rule analysis. The lower limits of support and confidence are set to 0.02 and 0.1 respectively, and we get the strong association rules shown in Table 5. These strong association rules are consistent with the research topics in cluster analysis, which also verify the result of cluster analysis.

\subsection{Social network analysis}

Through the analysis of the high frequency keywords' degree centralization, we can know the 
research directions and hotspot in this field. We import the co-word matrix into the Ucinet6.0, then the analysis of degree centrality is generated, as shown in Figure 3. The larger the keyword node in the figure, the more attention the subject represented by keywords receive in the research of this field.

It can be seen from Figure 3 that education quality, quality management and curriculum provision have the highest degree centralization, which reflects the main objectives of the research. The keywords of industrial engineering have a large degree centralization, which indicates that there are more education reforms applying QFD to industrial engineering majors. The degree centralization of keywords such as innovation ability, innovative talents, applied talents and practical ability is relatively large, indicating that these aspects are the main concerns of QFD application research. Keywords such as PDCA cycle and management talent are at the edge of the network, which shows that they are not the focus of current research, but may become the future development direction.

Table 5 Strong association rules.

\begin{tabular}{|c|c|c|c|c|c|c|}
\hline TID & lhs & & rhs & support & confidence & lift \\
\hline 1 & $\{$ PDCA cycle $\}$ & $\Rightarrow$ & $\{$ Laboratory $\}$ & 0.020 & 1.000 & 33.000 \\
\hline 2 & $\begin{array}{l}\text { \{Education quality, Evaluation } \\
\text { system\} }\end{array}$ & $\Rightarrow$ & $\begin{array}{l}\text { \{Entrepreneurship } \\
\text { education }\}\end{array}$ & 0.020 & 1.000 & 24.750 \\
\hline 3 & $\{\mathrm{TRIZ}\}$ & $\Rightarrow$ & $\{$ Innovation ability $\}$ & 0.020 & 0.667 & 16.500 \\
\hline 4 & $\{$ Entrepreneurship education $\}$ & $\Rightarrow$ & $\{$ Evaluation system $\}$ & 0.030 & 0.750 & 14.850 \\
\hline 5 & $\{$ Hotel management major $\}$ & $\Rightarrow$ & $\{$ Curriculum provision $\}$ & 0.030 & 1.000 & 9.900 \\
\hline 6 & $\{$ Practice ability $\}$ & $\Rightarrow$ & $\{$ User needs $\}$ & 0.020 & 0.667 & 9.429 \\
\hline 7 & $\{$ Economic management major $\}$ & $\Rightarrow$ & $\{$ Curriculum system $\}$ & 0.020 & 0.400 & 4.950 \\
\hline 8 & $\{$ Entrepreneurship education\} & $\Rightarrow$ & $\{$ Education quality\} & 0.020 & 0.500 & 3.808 \\
\hline 9 & \{Practice teaching\} & $\Rightarrow$ & $\{$ Quality management $\}$ & 0.020 & 0.500 & 3.536 \\
\hline 10 & $\{$ Evaluation system $\}$ & $\Rightarrow$ & $\{$ Education quality\} & 0.020 & 0.400 & 3.046 \\
\hline
\end{tabular}

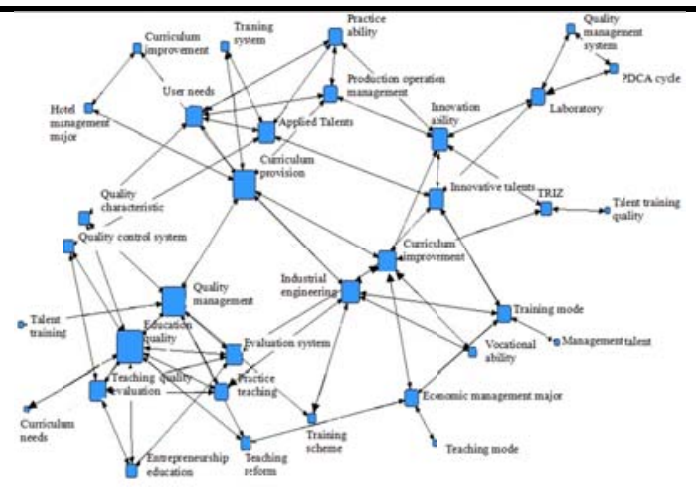

Figure 3 The analysis of degree centrality.

\section{Conclusion}

Through the bibliometric analysis of the application of QFD in the field of China higher education, the following conclusions are obtained:

(1) The number of research literatures on the application of QFD in China higher education is few, and the breadth and depth of research need to be strengthened. The publication of the papers are all higher education institutions and the papers are mainly co-authored. However, the distribution of researchers are relatively dispersed, and a mature research team has not yet been formed.

(2) The journals applied by QFD in China higher education are mainly "Value Engineering", 
"Research and Exploration in Laboratory", "Research in Higher Education of Engineering ", "Modern Education Management", "Education Forum", "Education Modernization" and so on.

(3) The subject of QFD applied in China higher education can be divided into: Laboratory quality management, education quality evaluation, hotel management major curriculum system improvement, talent training scheme and quality management, industrial engineering and economic management major talent training mode improvement, innovative talents training, application of practical talent training. The analysis of association rules verifies the division of research topics in cluster analysis.

(4) Education quality, quality management and curriculum provision are the focuses of QFD application in higher education.

\section{Acknowledgements}

This research was partially supported by the quality engineering projects in university of Anhui province (2015jyxm032).

\section{References}

[1] Clarke, A.M., Hough, M.J. and Stewart, R.F. (1984) University Autonomy and Public Policies: A System Theory Perspective. Higher Education, 13, 23-48.

[2] Akao, Y. (1972) New Product Development and Quality Assurance Deployment System. Standardisation and Quality Control, 25, 243-246.

[3] Chan, L.K. and Wu, M.L. (2002) Quality Function Deployment: A Literature Review. European Journal of Operational Research, 143, 463-497.

[4] Sun J.H. and Chen L. (2010) Research on the Application of QFD in Higher Education Quality Improvement. Shanghai Management Science, 32, 111-112.

[5] Pritchard A. (1969) Statistical Bibliography or Bibliometrics?. Journal of Documentation, 25, 348-349. 